\title{
Tissue Engineered Conduits for Pediatric Cardiac Surgery: State of the Art
}

\author{
Irina Zhuravleva1, Ilya Soynov²*, Nataliya Nichay², Yuriy Kulyabin², Alexey Zubritskiy², Alexey Voitov² and \\ Alexander Bogachev-Prokophiev² \\ ${ }^{1}$ Laboratory of Bioprostheses, Siberian Biomedical Research Center Ministry of Health Russian Federation, Russia \\ ${ }^{2}$ Department of Congenital Heart Surgery, Siberian Biomedical Research Center Ministry of Health Russian Federation, Russia
}

Submission: May 17, 2017; Published: June 14, 2017

"Corresponding author: Ilya Soynov, Department of Congenital Heart Surgery, Siberian Biomedical Research Center Ministry of Health Russian Federation, 15 Rechkunovskaya Street, 630055 Novosibirsk, Russia, Tel: +79134548752; Fax: 73833322437; Email: i_soynov@mail.ru

Abstract

In this review we present the modern tendencies in the field of the tissue-engineered implants for pediatric cardiac surgery.

\section{Introduction}

Currently, two approaches to create the tissue-engineered cardiovascular implants (CVI) exist-growing in the bioreactor by filling the bioresorbable polymer scaffold with auto-or alloCells, and implantation of the bioresorbable scaffold. Both of them consist of similar logical sequence:

I. The creation of bioresorbable scaffold (the method of electro spinning is usually used).

II. Cellular filling of the scaffold.

III. Structural self-organization under the influence of external and internal conditions into a viable graft similar to the replaced element in anatomical and functional respect.

The first approach is attractive for the possibility of obtaining a fully formed, ready-made transplant with a close to natural microarchitecture. The following conditions are necessary: a sufficiently high rate of resorption of the scaffold with simultaneous structural self-organization of the tissue and the acquisition of anatomical and functional characteristics identical to the replaced element. However, it is currently unsuitable for widespread use in clinical settings due to significant technological difficulties, short storage times for such transplants, and a number of side effects that may occur when using an alloCell resource. To focus on the autologous cell resource in daily clinical practice is impossible. That is why the work in this direction never came out outside of the experiment. Therefore, in modern conditions, the potential for realizing the direction associated with the creation of implantable, bioresorbable in situ scaffolds is much higher. This approach provides the technological and standardization required in any production, including biotechnology. Ready-made scaffolds can be stored sterile for a sufficiently long period, which is very important for clinical practice. An important aspect is also that in this approach only the autocells are always used to "grow" an organ or tissue in situ [1].

\section{The development of tissue engineering: from experiment to practice}

Thefirsttissue-engineered construction-a polycaprolactone/ polyglycolic acid scaffold seeded with autologic vein cells - was implanted in pulmonary artery position to a human in 1999 by Shinoka [2]. The program of clinical implication of tissueengineered right-sided conduits for congenital heart diseases repair was introduced in Nationwide Children's Hospital (Columbus, OH) in the USA in 2011. Studies, which have been performed under the tissue-engineering program supervised by Shinoka \& Breuer [2,3] allow to identify some consistent patterns determining modern trends of cardiovascular tissueengineering development [3].

On the one hand, it has been proven that implanted polymeric scaffolds are replaced by a living, self-renewing tissue, and therefore have a growth potential, which is important for pediatric cardiac surgery. On the other hand, it was revealed that cells filling the scaffold in vitro before the implantation, leave it during the first days after their persistence in the recipient, and the main cellular filling is performed at the expense of cells which penetrate the scaffold from the blood flow. The 
inflammation reaction and the specific signaling, accompanying it, play an important role in this case [3].

In this connection an alternative approach of the creation of tissue-engineered construction has been intensified. It is to change the surface of the scaffolds (so-called "scaffold functionalization") providing a cellular filling of the scaffold in situ. This approach allows to avoid the traumatic procedure of obtaining autogenic cellular material, and also the cell culturing in vitro - the expensive procedure carrying a large number of risks. The conception of functionalization is based on the creation of conditions for adhesion of cells from the blood flow to the scaffold, emphasizing endothelial cells and their precursors. According to researchers' opinion, such adhesion has to be provided by antibodies (for example, anti-CD34 or anti-CD133), derivatives of fibronectin (RGD- and REDV-peptides), laminin (YIGRS-peptide), heparin or growth factors (VEGF, TGF, etc.) [4].

But all these molecules, except antibodies, do not have any selectivity and might attract different types of other cells to the scaffold, moreover it is impossible to forecast a further differentiation of these cells. Thus, a differentiation of endothelial cells to mesenchymal was obtained while using TGFb1 [5], when SDF1 $\alpha$ was used-the precursors of smooth muscle cells fill the scaffold [6]. Even in case of using of seemed to be selective anti-CD34 antibodies, a massive neointimal hyperplasia was obtained as complication. In vivo cell seeding with anti-CD34 antibodies successfully accelerates endothelialization, but stimulates intimal hyperplasia in porcine arteriovenous expanded polytetrafluoroethylene grafts [7]. Currently, one of the most effective approach is the functionalization of scaffolds with RGD-peptide which allows to enhance reendothelization in situ by recruiting of EPC [8]. Based on this method, Xeltis company (Switzerland-Netherlands) has created non-valved cavopulmonary conduit, first implantation of which was performed in 2013 "A.N. Bakoulev Scientific Center for Cardiovascular Surgery" [9].

Nowadays, first clinical implantations of valved conduits have been already performed, and preclinical testing of valves for aortic implantation has been started. The company characterizes the last product as more complex due to the implanted scaffold must withstand high hemodynamic loads at the stage of resorption and cellular filling. An important innovative direction of the Netherland's department of company is the development of tissue-engineered transcatheter implant for pulmonary valve replacement named Life Valve [10]. Xeltis Company has achieved such significant success by the virtue of the cooperation with two large European universities - University of Technology (Eindhoven, The Netherlands) and University Zürich, (Zürich, Switzerland), where extensive tissue-engineering programs are carried out, and also with leading surgeons in Switzerland and Germany.

Analysis of the evolutionary development of the problem shows that further progress in the tissue-engineering will be related to the translational researches which use the last achievements of chemistry of polymers and molecular biology. For example, the original study of Chinese researchers, published in 2015, have not received an impression in world literature yet, justifies the possibility of RNA aptamers using for selective homing of CD133+ endotheliocytes precursors on the tissueengineered matrix [11]. Searching for polymers is directed to the synthesis of supramolecular compounds providing a controlled resorption, customized porosity in each layer of construction with the perspective to the formation of similar natural tissue layers, and mimicry of the biochemical properties of replaced tissue [12].

At the present stage of the development of this branch of science, a great interest is the study of the possibility of combining advantages of regenerative technologies and minimally-invasive transcatheter implantation of CVS elements. This approach has been intensively developed in recent years, as evidenced by the publication of the previously mentioned combined group of researchers from universities of Zurich and Eindhoven $[13,14]$, and also researchers from Munich's Ludwig Maximilians University and Technical University [15], and University of Aachen [16].

\section{Conclusion}

Future development of the tissue engineering, regardless of the chosen direction, is not possible, until the following problems have to be solved:

A. Selection from a wide range of already existing polymers or synthesis of new polymers to create the scaffolds that meet the following characteristics: biocompatibility; the predicted rate of resorption, not associated with the individual variability of the recipient environment and providing an optimal time balance "polymer resorption - cellular filling and tissue self-organization"; adequate elastic-strength properties and porosity of the implant throughout the entire period of cellular filling and remodeling;

B. Improvement of the electrospinning devices and methods, which allow fine-tuning the nanostructure of different scaffold layers and obtaining the scaffolds of complex shape (for example, heart valves, valved conduits, fragments of the valved venous wall);

C. Search for optimal cellular attractants for selective filling of the different scaffold layers by cells with the aim of obtaining the tissue-engineered structure, that is similar to natural, providing controlled differentiation of cells and increasing cell mass to form adequate tissue structure de novo.

\section{References}

1. Kehl D, Weber B, Hoerstrup SP (2016) Bioengineered living cardiac and venous valve replacements: current status and future prospects. Cardiovasc Pathol 25(4): 300-305. 


\section{Current Trends in Biomedical Engineering \& Biosciences}

2. Shinoka T, Imai Y, Ikada Y (2001) Transplantation of a tissueengineered pulmonary artery. N Engl J Med 344(7): 532-533.

3. Vogel G (2011) Tissue engineering. Mending the youngest hearts. Science 333(6046): 1088-1093.

4. Emmert MY, Fioretta ES, Hoerstrup SP (2017) Translational Challenges in Cardiovascular Tissue Engineering. J Cardiovasc Transl Res 10(2) 139-149.

5. Wang H, Leinwand LA, Anseth KS (2014) Cardiac valve cells and their microenvironment-insights from in vitro studies. Nature Reviews Cardiology 11(12): 715-727.

6. Yin Y, Zhao X, Fang Y, Yu S, Zhao J, et al. (2010). SDF-1 $\alpha$ involved in mobilization and recruitment of endothelial progenitor cells after arterial injury in mice. Cardiovascular Pathology 19(4): 218-227

7. Rotmans JI, Heyligers JM, Verhagen HJ, Velema E, Nagtegaal MM, et al. (2005) In vivo cell seeding with anti-CD34 antibodies successfully accelerates endothelialization but stimulates intimal hyperplasia in porcine arteriovenous expanded polytetrafluoroethylene grafts. Circulation 112(1): 12-18.

8. Kang TY, Lee JH, Kim BJ, Kang JA, Hong JM, et al. (2015) In vivo endothelization of tubular vascular grafts through in situ recruitment of endothelial and endothelial progenitor cells by RGD-fused mussel adhesive proteins. Biofabrication 7(1): 015007.

9. Bockeria LA, Svanidze O, Kim A, Shatalov K, Makarenko V, et al. (2017) Total Cavo-Pulmonary Connection with a New Bio-Absorbable Vascular Graft First Clinical Experience. J Thorac Cardiovasc Surg 153(6): 15421550 .
10. Schmitt B, Spriestersbach H, O H-Icí D, Radtke T, Bartosch M, et al (2016) Percutaneous pulmonary valve replacement using completely tissue-engineered off-the-shelf heart valves: six-month in vivo functionality and matrix remodelling in sheep EuroIntervention 12(1): $62-70$

11. Chen W, Zeng W, Sun J, Yang M, Li L, et al. (2015) Construction of an Aptamer-SiRNA Chimera-Modified Tissue-Engineered Blood Vessel for Cell-Type-Specific Capture and Delivery. ACS 9(6): 6069-6076.

12. Morgan KY, Sklaviadis D, Tochka ZL, Fischer KM, Hearon K, et al. (2016) Multi-Material Tissue Engineering Scaffold with Hierarchical Pore Architecture. AdvFunct Mater 26(32): 5873-5883.

13. Driessen-Mol A, Emmert MY, Dijkman PE, Frese L, Sanders B, et al. (2014) Transcatheter tissue engineered heart valves. Expert Rev Med Devices 11(1): 15-21.

14. Driessen-Mol A, Emmert MY, Dijkman PE, Frese L, Sanders B. et al (2014) Transcatheter Implantation of Homologous "Off-the-Shelf" Tissue-Engineered Heart Valves With Self-Repair Capacity: Long-Term Functionality and Rapid In Vivo Remodeling in Sheep. J Am CollCardiol 63(13): 1320-1329

15. Koenig F, Lee JS, Akra B, Hollweck T, Wintermantel E, et al. (2016) Is Transcatheter Aortic Valve Implantation of Living Tissue-Engineered Valves Feasible? An In Vitro Evaluation Utilizing a Decellularized and Reseeded Biohybrid Valve. Artificial Organs 40(8): 727-737.

16. Moreira R, Velz T, Alves N, Gesche VN, Malischewski A, et al. (2015) Tissue-Engineered Heart Valve with a Tubular Leaflet Design for Minimally Invasive Transcatheter Implantation. Tissue Eng Part C 21(6): 530-540

\section{Your next submission with Juniper Publishers will reach you the below assets}

- Quality Editorial service

- Swift Peer Review

- Reprints availability

- E-prints Service

- Manuscript Podcast for convenient understanding

- Global attainment for your research

- Manuscript accessibility in different formats

( Pdf, E-pub, Full Text, Audio)

- Unceasing customer service

Track the below URL for one-step submission https://juniperpublishers.com/online-submission.php 